\title{
A mindful model of sexual health: A review and implications of the model for the treatment of individuals with compulsive sexual behavior disorder
}

\author{
GRETCHEN R. BLYCKER ${ }^{1,2}$ and MARC N. POTENZA ${ }^{3,4,5 *}$ \\ ${ }^{1}$ College of Nursing, University of Rhode Island, Kingston, RI, USA \\ ${ }^{2}$ Hälsosam Therapy, Jamestown, RI, USA \\ ${ }^{3}$ Departments of Psychiatry and Neuroscience and the Child Study Center, School of Medicine, Yale University, New Haven, CT, USA \\ ${ }^{4}$ Connecticut Council on Problem Gambling, Wethersfield, CT, USA \\ ${ }^{5}$ Connecticut Mental Health Center, New Haven, CT, USA
}

(Received: September 20, 2018; revised manuscript received: November 12, 2018; accepted: November 22, 2018)

\begin{abstract}
Background and aims: Mindfulness-based approaches, derived from centuries of eastern philosophy and practice, have been increasingly incorporated into western medicine. For example, data support the efficacy of mindfulnessbased therapies to reduce stress and promote mental health. Methods: In this study, we briefly review models and approaches to sexual health in the context of considering compulsive sexual behavior disorder, describe mindfulnessbased approaches to stress, addiction, and compulsive sexual behaviors, and present a Mindful Model of Sexual Health (MMSH) that incorporates elements of eastern and western philosophies. We further illustrate the clinical utility of the MMSH in a clinical case description. Results: We propose the MMSH as a holistic and integrative model that honors and acknowledges individual differences and provides mindfulness-based tools and practices to support individuals to proactively manage, balance, and promote sexual and mental health. The MMSH may be used as a framework to organize information regarding physical, mental, emotional, sexual, and relational health, as well as a conceptual map offering navigational skills to access information within one's mind/body to make informed decisions to promote well-being regarding sexual satisfaction and health. In its organizational structure, the MMSH is divided into eight domains that are theoretically linked to biological functions and may be used to identify and overcome barriers to sexual health through mindful inquiries in clinical practice or educational settings. Discussion and conclusion: Given its focus on awareness of interoceptive processes through mind/body connectedness, the MMSH may resonate with a wide range of individuals, including those with compulsive sexual behavior disorder.
\end{abstract}

Keywords: mindfulness-based therapies, sexual health, compulsive sexual behavior disorder, hypersexuality, integrative sexual wellness education, respect-based sexuality

\section{INTRODUCTION}

The promotion of sexual health is an important endeavor. Many individuals experience concerns relating to sexual health including engagement in compulsive sexual behaviors, experiencing sexual traumas (Maltz, 2001; Ogden, Minton, Pain, Siegel, \& van der Kolk, 2006; Tekin et al., 2016; Van der Kolk, 2015; van der Kolk et al., 1996), and engaging in impulsive sexual behaviors that may place themselves or others at risk for sexually transmitted infections or other health concerns (Erez, Pilver, \& Potenza, 2014; Kraus et al., 2018). Concerns regarding unhealthy sexual behaviors may be increasing in the setting of the growth of Internet pornography and the prevalence and correlates of problematic pornography consumption (Kor et al., 2014; Kraus, Martino, $\&$ Potenza, 2016), the use of digital technologies to engage in sexual behaviors and related mental and physical health correlates (Turban, Potenza, Hoff, Martino, \& Kraus, 2017), and the inclusion of compulsive sexual behavior disorder in the 11th edition of the International Classification of Diseases
(ICD-11) by the World Health Organization (WHO; Kraus et al., 2018). In the current environment, developing models for the promotion of sexual health has considerable public health implications.

The WHO (2006) presents a holistic and comprehensive definition of sexual health as being, "a state of physical, emotional, mental and social well-being in relation to sexuality; it is not merely the absence of disease, dysfunction or infirmity. Sexual health requires a positive and respectful approach to sexuality and sexual relationships, as well as the possibility of having pleasurable and safe sexual experiences, free of coercion, discrimination, and violence. For sexual health to be attained and maintained, the sexual rights of all persons must be respected, protected and fulfilled." Other agencies, such as the US Center for Disease

* Corresponding author: Marc N. Potenza, MD, PhD; Connecticut Mental Health Center, Room S-104, 34 Park Street, New Haven, CT 06519, USA; Phone: +1 203737 3553; Fax: +1 203737 3591; E-mail: marc.potenza@yale.edu

This is an open-access article distributed under the terms of the Creative Commons Attribution-NonCommercial 4.0 International License, which permits unrestricted use, distribution, and reproduction in any medium for non-commercial purposes, provided the original author and source are credited, a link to the CC License is provided, and changes - if any - are indicated. 
Control and Prevention, promote a similar definition and include a spiritual dimension (Douglas \& Fenton, 2013). Since sexual, mental, and physical health are interconnected, there may be specific benefits to an integrated holistic perspective. To fulfill a state of well-being regarding sexuality, it is important to identify barriers to health, respect, safety, and pleasure and have awareness and skills regarding how to actively promote positive sexual experiences.

In this article, we review models of sexual health in order to provide an historical background for the introduction of a new sexual health model based on a growing body of research in which mindful practices that increase awareness of somatic states (Mehling et al., 2012) are beneficial in promoting sexual health (Brotto, 2013; Brotto, Basson, \& Luria, 2008; Brotto, Chivers, Millman, \& Albert, 2016; Mize, 2015; Silverstein, Brown, Roth, \& Britton, 2011; Stephenson \& Kerth, 2017). Given the tenets of the model, we will also describe how mindfulness-based approaches have been integrated into western medicine to address, such concerns as stress, depression, and addictions. Mindful attention may be described as non-judging, patient, and respectful awareness (Kornfield, 2009). The four foundations of mindfulness include focusing mindful awareness to explore the body, feelings, mind (i.e., thoughts, images, stories, judgments, beliefs, etc.), and the dharma [i.e., truth, elements that contribute to experiences, and principles and laws that are operating (Kornfield, 2009)]. Dharma derives from Sanskrit and refers to "cosmic law and order" and includes teachings that promote generosity, virtue, and loving-kindness. Although originally conceptualized within a Buddhist/religious context, mindfulness has been adopted and adapted within western medical contexts as detailed further below. Mindfulness may be applied to promote psychological well-being through the four principles of transformation taught using the acronym, RAIN; recognition of what is so, acceptance, investigation with mindful attention of experiences in body, feelings, mind, and reality, and non-identification (Kornfield, 2009).

Mindfulness-based approaches have been developed and have shown efficacy for reducing stress (Kabat-Zinn \& Hanh, 1990), treating pain-related disorders (Astin, Shapiro, Eisenberg, \& Forys, 2003), decreasing depression (Brewer, Bowen, Smith, Marlatt, \& Potenza, 2010), and promoting abstinence or other positive outcomes in addictions (Hendershot, Witkiewitz, George, \& Marlatt, 2011; Price \& Smith-DiJulio, 2016; Price, Wells, Donovan, \& Rue, 2012). In treating addictions, mindfulness-based relapse prevention treatment utilizing SOBER (stop, observe, breath focus, expand awareness, and respond consciously) breathing meditation and urge surfing may decrease reactivity to triggers, craving, and negative affect (Bowen \& Marlatt, 2009; Brewer et al., 2010; Hendershot et al., 2011; Witkiewitz et al., 2014). While the mechanisms are still incompletely understood, mindfulness approaches may instruct individuals that urges and cravings are transient events that are dynamic in which they change over time, and through this understanding and a calm acceptance, they may alter maladaptive patterns of behavior (Bowen et al., 2009). Investigations of the neural underpinnings of mindfulness-related practices (e.g., meditation) have demonstrated differences in engagement of attentional and default mode networks (Brewer et al., 2011, Garrison, Zeffiro, Scheinost, Constable, \& Brewer, 2015). Building and practicing mindful skills have been shown to decrease attempts to act on cravings as well as aversions through avoiding or seeking to escape from unwanted thoughts or inner experiences by increasing awareness and clarity regarding habits that may cause prolonged pain and suffering (Bowen, Chawla, \& Marlatt, 2011; Brewer, Davis, \& Goldstein, 2013). While a case report using meditation awareness training to treat sex addiction suggested clinically significant improvements (Van Gordon, Shonin, \& Griffiths, 2016), a framework for considering mindfulness-based therapies for treating compulsive sexual behaviors is lacking. Mindfulness frameworks that have been proposed for promoting sexual health may not be applicable to treating individuals with compulsive sexual behavior disorder. For example, the mindful-awareness in body-oriented therapy that focuses on teaching interceptive awareness has been applied to helping individuals recover from childhood sexual abuse, substance addictions, and sexual difficulties and includes elements of physical touch that may not be appropriate in clinical settings in helping people with compulsive sexual behavior disorder (Carvalheira, Price, \& Neves, 2017; Price, 2005; Price \& Smith-DiJulio, 2016; Price \& Hooven, 2018; Price, Thompson, \& Cheng, 2017; Price et al., 2012). As such, alternate models and approaches are needed.

To address this need, we propose a Mindful Model of Sexual Health (MMSH; Blycker, 2018). In the framework of the model, mindful inquiries that increase interoceptive awareness may promote access to present-moment information from one's body and mind about intrapersonal and interpersonal experiences. Such information may guide informed decisions about sexual health by increasing sexual intelligence and skillfully awakening sexual empathy and awareness. In this context, one may also more effectively target root factors contributing to various problems relating to sexual dissatisfaction and harm.

The MMSH promotes the cultivation of present-centered rather than performance-focused sexuality that is more process-oriented rather than mechanistic or pathologyfocused. This integration and assessment of information through body awareness and interoception may facilitate the evolution and growth of sexuality with emotional development and interpersonal growth. Disconnection and dissociation may lead to sexual dysfunction and psychopathology and these processes may be targeted and countered through increasing present-moment awareness during sexual behaviors (Carvalheira et al., 2017; Price \& Thompson, 2007).

Personal feedback from hundreds of university students (gleaned through teaching human sexuality courses over the past decade) has suggested the need for and their desire to have access to sexual health education that includes and transcends models focused on clinical aspects of contraception and sexually transmitted infections. Specifically, a model that includes self-exploration of one's "authentic sexual self," a deepened investigation of conscious and wellness-informed decision-making processes, and healthy and effective relational communication skills are of significant interest. The MMSH aims to address these topics in 
order to promote public health and decrease problematic or compulsive sexual behaviors and their negative impacts. Given the complexities in navigating the deeply personal aspects of sexual health in a digital world rife with external sexual messages, there is a need for more effective education regarding the cultivation of personal emotional, mental, and sexual health and well-being. The ubiquity and easy access of online sexually explicit material may place individuals, and perhaps especially youth, at elevated risk for being influenced by pornography-informed gendered sexual scripts, which may embed codes of behavior and guide sexual experiences (Sun, Bridges, Johnson, \& Ezzell, 2016). Pornographic sexual scripts often include sexual objectification, female degradation, and male to female aggression (Bridges, Wosnitzer, Scharrer, Sun, \& Liberman, 2010; Gorman, Monk-Turner, \& Fish, 2010). Although data indicate that females are less likely to view pornography than males, those females who view pornography are more likely to adopt pornographic sexual scripts (Bridges, Sun, Ezzell, \& Johnson, 2016). A significant association has been reported between men's pornography use and reliance on the pornographic script for maintaining sexual arousal in dyadic sexual encounters, and excessive pornography use has been related to diminished enjoyment of intimacypromoting behaviors such as kissing and caressing (Sun et al., 2016).

In this digital age, it is important to have a balance of health-promoting sex education that may provide resiliency to negative impacts of problematic sexual scripts and that also proactively works to prevent the development of problematic sexual behaviors. The MMSH aims to promote self-awareness, self-understanding, and skills to access inner information to increase clarity and confidence in making choices that promote health. Desire, sexual energy, sensory feelings, arousal, sexual functioning, sexual satisfaction, sexual self-esteem, and relational intimacy are influenced by several factors. The MMSH aims to provide a template to organize, assess, and manage the multidimensional factors that may influence sexual health and well-being.

\section{SEXUAL HEALTH AND FUNCTIONING MODELS}

Multiple models for promoting sexual health have been proposed, and a complete review is beyond the scope of the current manuscript. Some early models sought to normalize previously stigmatized behaviors, such as masturbation (Ellis, 1911) and a spectrum of sexual orientations (Kinsey, Pomeroy, \& Martin, 1948; Kinsey, Pomeroy, Martin, \& Gebhard, 1953), and challenge preconceived notions regarding narrow and problematic conceptualizations of human sexuality, such as the sexual double standard involving social biases regarding sexual permissiveness or pleasure for males and females (Crawford \& Popp, 2003). A fourphase linear model of sexual functioning introduced sensate focus, a process still used in couple's therapy (Masters, Johnson, \& Kolodny, 1982). Sensate focus trains couples to give and receive full-body sensual loving touch in a present and attuned way, bringing awareness to their direct in-themoment sensual experiences, which are then eventually integrated into erotic experiences after habits of "spectatoring" and being performance-focused are diminished. Sensate focus may be viewed as a precursor to mindfulnessbased approaches that are increasingly being investigated today. Mindfulness-based approaches that include training of interoception to increase body awareness and body connection may be effective in the treatment of sexual functioning concerns (Brotto, Krychman, \& Jacobson, 2008; Brotto, Mehak, \& Kit, 2009; Brotto, Seal, \& Rellini, 2012; Carvalheira et al., 2017; Mehling et al., 2012; Mize, 2015; Silverstein et al., 2011).

Theories have been proposed that focus on sex differences in sexual arousal, functioning, motivation, and pleasure. Models have been proposed that consider the particular relevance to women for roles of conscious appraisal and positive affective states that may contribute to experiencing and expressing motivations for interpersonal sexual experiences and that may involve integration of information from mind, body, and interpersonal relationship through psychological and biological processing (Basson, 2002, 2005). A proposed biobehavioral model (Diamond, 2003) differentiates romantic love and affectional bonding from sexual desire, describes their bidirectional relationship, and communicates how these factors may relate to male and female sexuality (Diamond, 2003). The same author proposed that sexuality fluidity, defined as situationally dependent flexibility in female sexual responsiveness, is an important consideration in these processes (Diamond, 2008). Another model proposed anchor points in a hierarchy of positive and negative sexual interactions (Maltz, 1995). This model, developed for use in therapy and psychosexual education, proposed sexual energy as a natural and powerful force that, depending on factors of expression and context of experience, may be positively channeled toward optimum experience or negatively expressed toward creating harm. The term sexual energy was used in the model and may resonate with eastern concepts of the chakra system. In western medicine, such energies may be conceptualized as senses, feelings, motivations, drives, or interests. In clinical settings, specific individuals may have unique conceptual or sociocultural orientations and meeting individuals where they are, and acknowledging their frameworks may help with therapeutic alignment and promote positive clinical outcomes. In clinical settings, the model describes the importance of clear communication between partners, the establishment of safety and trust, and the relevance of "authentic sexual intimacy as a peak experience in human sexual relating" (Maltz, 1995). An intimacy-focused model for couple sexual satisfaction named, "Good Enough Sex," normalizes the changing nature of quality of sexual experiences as well as the importance of having reasonable expectations that allow for variable sexual expressions and meanings (McCarthy \& Wald, 2013). Additional contributions include practical application of clinical knowledge for individuals and couples to utilize present focus and mindful approaches to address sexual functioning difficulties including identifying a couple's unique sexual style, managing desire discrepancies, erectile dysfunction, and premature ejaculation within a supportive team-like fashion (McCarthy, 2004). Some models targeting compulsive or addictive engagement in sexual behaviors have focused on 
identifying and addressing past traumas (Carnes \& Adams, 2013). A recent model focusing on hypersexuality has considered roles for sexual urges, behaviors and satiation, as well as post-sexual satiation (Walton, Cantor, Bhullar, \& Lykins, 2017). Although questions have been raised regarding the extent to which and how this recent model may deviate from human sexuality cycles in general and prior models of addictive or compulsive sexual behaviors, a need for additional research seems particularly relevant given the inclusion of compulsive sexual behavior disorder in ICD-11 (Gola \& Potenza, 2018; Kingston, 2017).

\section{A MINDFUL MODEL OF SEXUAL HEALTH}

The development of the MMSH was influenced by eastern and western practices, philosophies, and sources including mindfulness, compassion, interoception, psychophysical awareness and connection, body energy constructs, ethical conduct, and psychological and sexual well-being. The training programs that informed the holistic perspective of the MMSH include clinical massage therapy training that focuses on body awareness and attunement; clinical training in mental health treatment using mindfulness-based approaches in the Hakomi method (Kurtz, 1997); clinical training to treat problematic sexual behaviors; yoga teacher training that integrates mind-body-spirit approaches; and education of college students in human sexuality, with exercises involving mindful explorations of sexual motivations, emotions, and experiences.

In its organizational structure, the MMSH utilizes the subtle body, or chakra system from Indian yoga, which has been proposed to link to interoceptive aspects of central nervous system function (Loizzo, 2014, 2016). The subtle body construct provides conceptual perspectives regarding sexual energy and desire. Sexual desire disorders are commonly considered the most challenging sexual difficulties to treat (Leiblum, 2006). Western operational definitions of sexual desire include having motivational sexual thoughts and fantasies to seek sexual stimuli (Meston, Goldstein, Davis, \& Traish, 2005). From a Buddhist psychology perspective, this may be seen as antithetical to eastern practices of mindfulness and instead approaches the emergence of sexuality in a way that is separate from the embodied experience and equates or measures sexual desire with thoughts and fantasies. Further research is needed to explore if this construct might be contributing to expectations, beliefs, and experiences that condition the sexual arousal system toward craving and a focus on seeking outside of oneself for cues to trigger sexual arousal and focus. The MMSH includes eastern perspectives and practices of cultivating skillfulness to increase awareness and acceptance of the changing inner states of experience within body, mind, motivation, sensation, and energy. Sexual energy, motivation, and/or desire are acknowledged as part of innate powerful life-force, and awakening kundalini energy has been proposed to contribute to balancing and connecting chakra centers throughout the subtle body (Dowman, 1996; Easwaran, 2007). The training of attention toward psycho-physiological changing states may allow for mindful cultivation and management of sexual energy/motivation/ desire within for the benefit of health, vitality, pleasure, and well-being, rather than something to chase, grasp onto, or access outside of oneself. This may have implications across many domains of sexual health and functioning from hypoactive/hyperactive desire disorders as well as compulsive sexual behaviors.

The organizing principles of the MMSH include the following:

- Respect-based sexuality that honors the rights of all human beings to experience their bodies as a safe place to enjoy their unique sexuality.

- Safety. Zero tolerance for anyone being exploited, used or abused in order for another to experience sexual gratification.

- Mindful connection. Development of this practice requires an interest in one's inner self and an openness and curiosity for discovery within. Cultivation of sexual intelligence and sexual empathy contributes to pleasure and satisfaction.

- Holism. Sexual, mental, and physical health are all interconnected.

- Integration of $\mathrm{mind} / \mathrm{body} / \mathrm{spirit}$ and eastern/western perspectives and practices.

The MMSH includes eight domains of well-being that are interrelated. Health and balance are proposed to involve assessment and integration of all eight domains that include physical health, sexual-emotional health, individuation, intimacy, communication, self-awareness, spirituality, and mindfulness. Within each of these domains, there exist aspects related to healthy expression and balance, possible barriers to health and balance, possible consequences, risks, or harms related to these barriers, and possible starting points for mindful inquiries for intrapersonal explorations. A general approach for using mindful inquiries that focus on the body, and the breath and move toward integration is presented in Table 1. Within each of the domains of the $\mathrm{MMSH}$, mindful inquiries may be generated to promote sexual health. A case example is presented to demonstrate how the model may be applied in clinical practice to help someone seeking treatment for compulsive sexual behavior (see case below and Table 2).

The physical health domain includes science-based information about health and involves taking responsibility for health maintenance and treatment. This includes practicing healthy ways to actively manage challenges and decrease stress responses within the body. Habits of selfcare include health-promoting lifestyle habits with sleep, diet, and exercise. Healthy connection with one's body includes mindful enjoyment of sensual pleasures.

The sexual-emotional health domain involves the management of the health and balance of the dynamic flow of change regarding inner emotional experiences as well as sexual and gender identity and expression. Cultivating connection with one's authentic sexual self includes developing positive sexual self-esteem (Potki, Ziaei, Faramarzi, Moosazadeh, \& Shahhosseini, 2017) as well as the continuing formulation of one's arousal template, or personal erotic meaning associated with physiological responses of sexual arousal. For healthy intrapersonal integration, selfawareness, understanding, and acceptance constitute important ongoing processes. In interpersonal sexual relationships, communicating information and desires from 
Table 1. Components of a mindful inquiry process in a mindful model of sexual health

Mindful model of sexual health: Mindful inquiry steps with body, breath, inquiry, and integration

Body:

"If comfortable for you, allow your eyes to close. Another option is to soften and allow your gaze to drop, so as to engage your "inner eyes." Focus your attention to include your whole physical body. With compassionate awareness, explore and note your direct experience of sensations and information throughout your body. Notice your automatic reactions to what you experience."

Breath:

"Focus on and feel the physiological changes that are happening with the inhale and exhale. Allow your inhale and exhale to invite your attention to stay with, return focus to, and deepen direct experience within the body. Continue to gently return focus to your breath, again and again."

Inquiry:

"Now expand and include awareness of sensations, emotions, images, impulses, words, memories, metaphorical representations, or whatever may arise on its own." Experiment with asking a mindful inquiry or an inner question and observe what emerges in response. Create space to allow and welcome whatever may arise. Let go of expectations of responses. Allow things to be shown to you. Observe with open curiosity, without judgment or interpretation of meaning. Be open and curious toward what the body/mind brings up to awareness to reveal and explore (i.e., an inquiry about self-compassion might bring up information about shame). Organizational beliefs operating below conscious awareness may, at times, seemingly contradict cognitive beliefs. Practice acknowledging and appreciating self-protective processes or mechanisms before evaluating whether they continue to serve healthy functioning (i.e., be open to exploring questions like, "How might this have served me in the past? How might this have protected me or met certain needs?").

Integration:

Attend to information from interoceptive awareness. Explore possible meanings of a mindful inquiry experience and what resonates as truth from this mindful and connected state. Integrate the meanings and any new perspectives into a cohesive narrative. Assess and reevaluate beliefs that have contributed to automatic patterns of thinking, seeing, or behaving. For example, acknowledge how coping or other processes may have been organized around self-protecting or surviving in the past Engage in a mindful and fresh evaluation about healthy functioning in present. Correct and clarify outdated beliefs, so that operational beliefs are in alignment with reality, truth, and the promotion of body/mind/ spirit health. Install updated beliefs into a new operating system. Ask, "Is there is anything else that would like to be expressed, acknowledged, known, shared or explored before closing the mindful experience?"
Purpose

Learn the active practice of being present with oneself. Practice slowing down, interrupt automatic reactivity, and create space between impulse and response.

Learn the active practice of returning focus on observing inner experience between mind-wandering, moments of distraction, or disconnection. The breath may serve as an anchor of attention in the present moment as well as a pathway to return to the present.

Within a state of presence, develop the mindful "witness" or "observer" to investigate subtle data that emerge anew from within. Practice a mindfully focused and managed holistic information-gathering process, which is different from automatically retrieving or operating from information from the past that may be distorted, harm-contributing, outdated, or not true. Learn to notice when cognitive processes jump to judgments or distorted perceptions.

Incorporate mindful acknowledgment and compassionate meeting of all domains of self. Cultivate a mindful and clear way to observe current state of how operating systems are functioning. Engage in a self-evaluation of efficacy of patterns of functioning. Create a conscious and mindfully informed narrative and identify practices that will integrate new perspectives and practices into setting goals for these realizations. one's authentic sexual self can be important for health and mutual understanding. Mindfulness-based skills may be utilized for the management of sexual energy, experiencing embodied eroticism, and cultivating a positive erotic selfconcept. Cultivating these connections within oneself may allow access to an inner resource of rejuvenating energy, pleasure, or motivation. Mindful connection may also facilitate authentic expression of sexual orientation, gender identity, and expression.

The individuation domain focuses on healthy selfesteem, worthiness, respect for self and others, confidence, and boundary maintenance. Exhibiting personal will, autonomy, appropriate use of power, self-direction, sexual agency, and choice may constitute aspects of healthy expression of individuation.

Healthy balance in the intimacy domain may involve experiences of connection, self-acceptance, and warmth and love toward oneself. Practicing compassion for self (personal) and humanity (universal) represent higher and deeper levels of cultivating wellness in this domain. Caring about a partner's inner experience and practicing growth in emotional and sexual empathy are examples of healthy intimacy. Using mindful awareness in determining boundaries that promote safety and earned trust are important in informing 


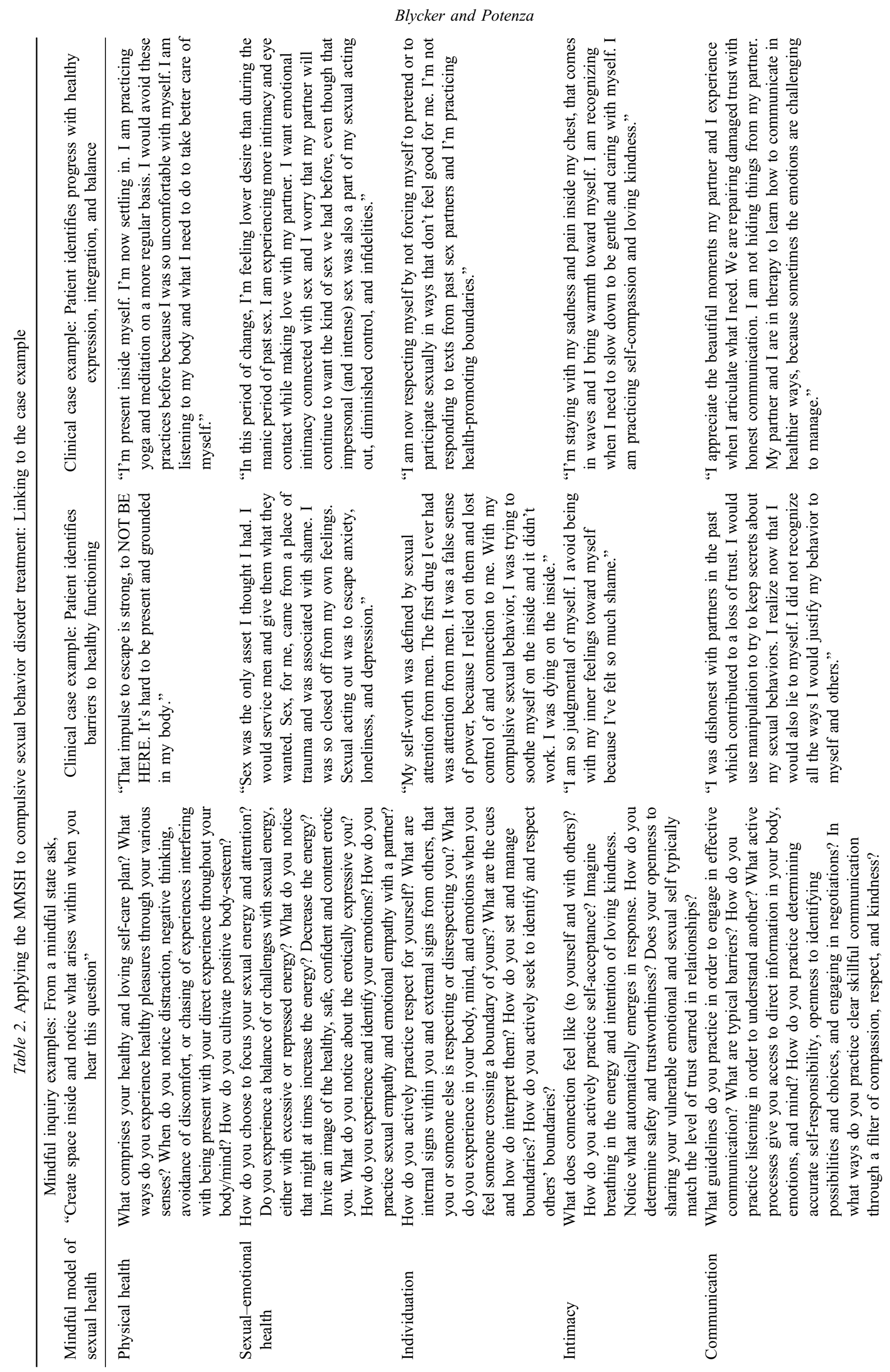



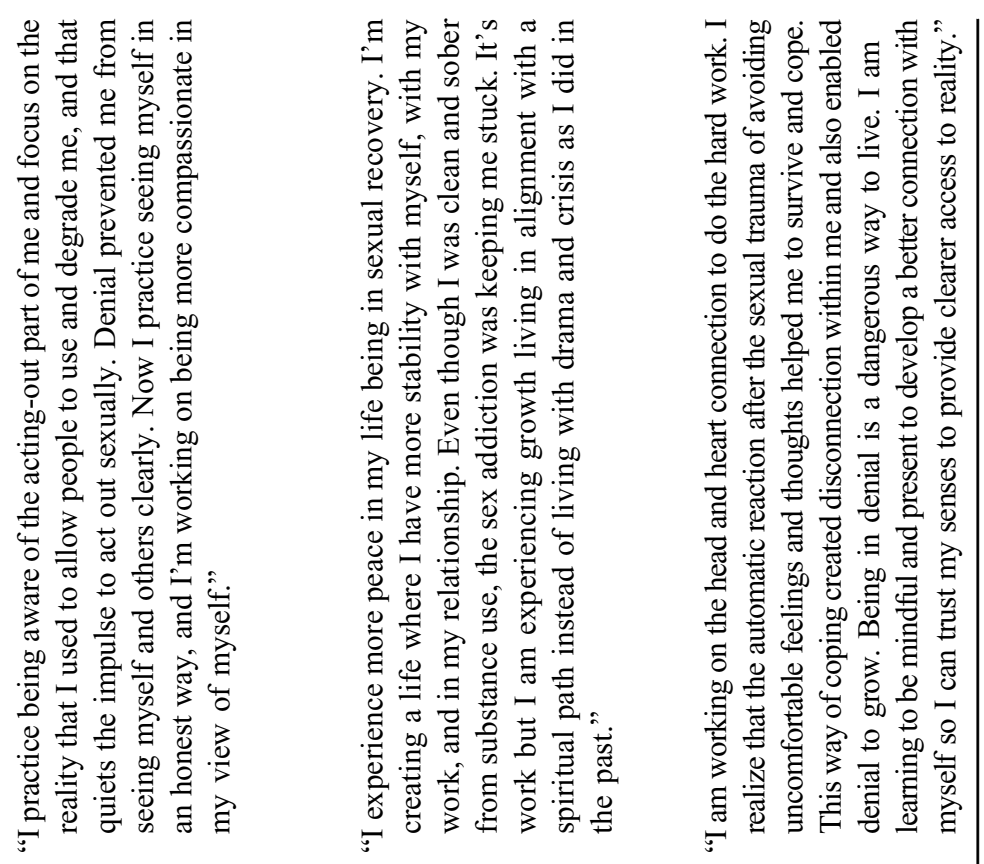

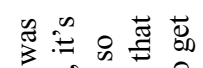

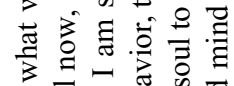

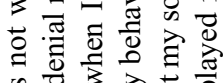

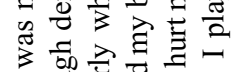

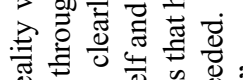

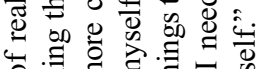

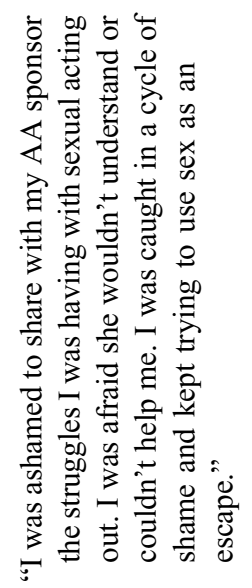

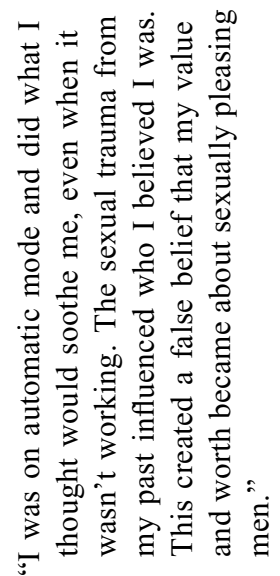

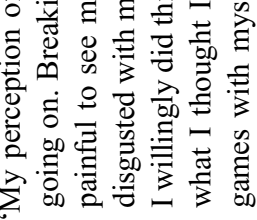

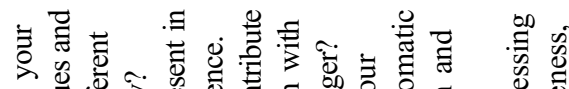

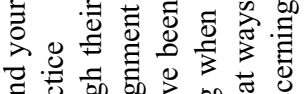

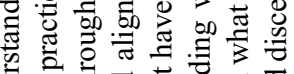

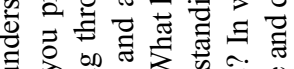

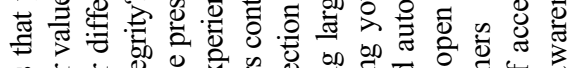

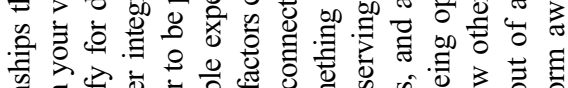

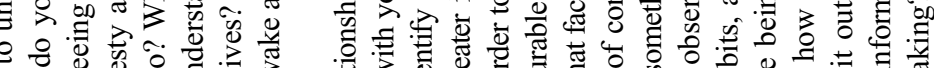

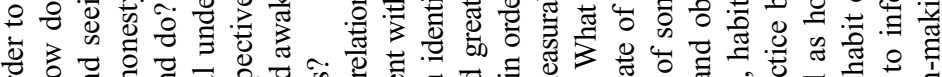

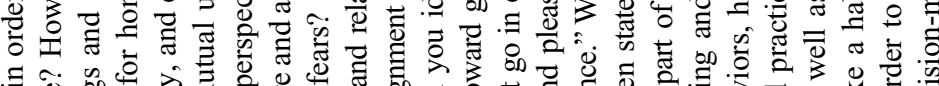

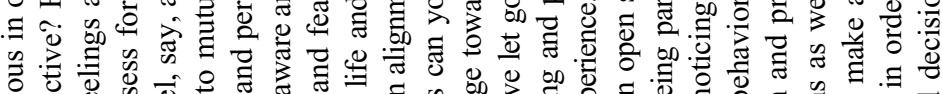

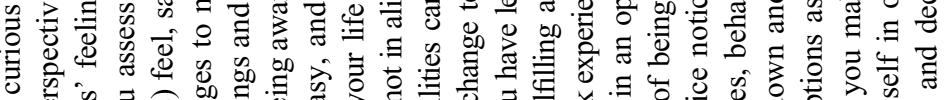

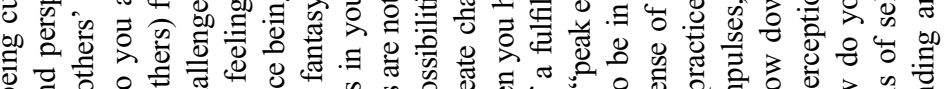

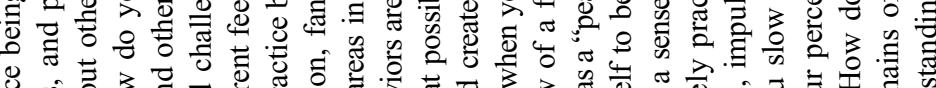
$\begin{array}{lll} & \\ 0\end{array}$

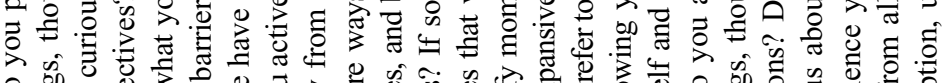

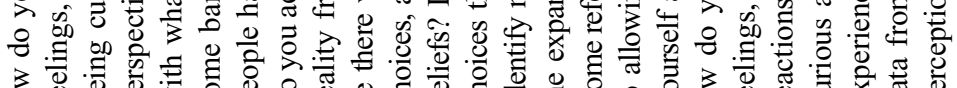

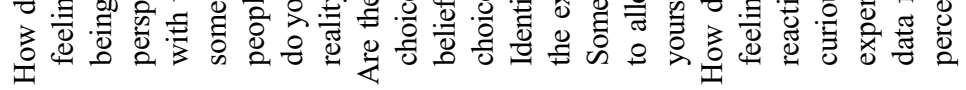


the depth of sharing of one's vulnerable emotional and/or sexual self with trusted people. Deeper levels of intimacy may contribute to more robust experiences of connection.

The communication domain may involve mindful selfawareness practice in accessing information within parts of oneself. Communicating this information with a partner often requires skillful sharing and open, receptive listening in seeking empathic understanding. Skillful interpersonal communication includes healthy effective rather than destructive communication (Garanzini et al., 2017) and may also include negotiations relating to balance of power and conflict resolution.

The self-awareness domain includes cultivation of skills that utilize flexibility with insight in order to stay present with one's own perception, emotions, and needs, while allowing space to see, hear, identify, acknowledge, and understand another's perception, emotions, and needs. Leading with curiosity toward cognitive empathy is helpful in the process of deepening understanding. In addition to practicing viewing from multiple perspectives, bringing clarity and honesty to self-awareness is paramount in identifying cognitive distortions, which misinform emotional experiences and perception. Justifications, excuses, and denial are all impediments to truth and to clearly seeing reality with respect to self, others, systems, or situations. Actively practicing being aware, being mindfully awake, and discerning truth from illusion or distortion are a moment-to-moment ongoing process.

The spirituality domain includes a felt sense of connection with something greater than oneself, including but not limited to; a life force, an entity, god or goddess, higher wisdom, higher power, or nature (Miller et al., 2018). Spiritual states include a felt sense of being present, open, and connected. The integration of sexuality and spirituality has been cited as important in the cultivation of an enlightened mind (Epstein, 2013). Skillfulness in this domain may include the ability to rest and relax into the tension created from the reality of the universal and personal aspects of existence. Acknowledging impermanence may allow for experiencing moments of acceptance of the unknown enough to surrender into letting go in a changing flow of experience. Healthy self-care in this domain may involve assessing for and managing safety with healthy boundaries when practicing a deep and vulnerable surrender. Barriers to spiritual states may include using thoughts and fantasies to distract from direct experience, enabling a false belief that escaping through exerting control of thoughts or experience will protect oneself from the unknown and uncertainty of being vulnerable. Bringing mindfulness-based skills to practice being aware of automatic reacting or grasping onto or chasing experiences as if one could own energy, possess desire, control others, and prevent change in others may represent problematic aspects seen in addictions and compulsive sexual behaviors.

The mindfulness domain is integrated with all previous seven domains. This promotes moments of being fully present, which Pema Chödrön has described as, "a wideawake state where your sense perceptions are wide open" (Haas, 2013). A mindful practice of focused compassionate attention within all domains of self and between self and others, with open and non-judgmental curiosity, is a valuable source for gathering information to guide decision-making processes. The mindful and conscious process of accessing, assessing, and evaluating internal bodily signals, sensations, and physiological processes comprises interoceptive awareness, and has been suggested as an underlying mechanism for mindfulness-based treatment approaches (Price et al., 2017).

\section{APPLICATION OF THE MMSH}

The MMSH may be utilized to create individualized/ personalized healthy self-care plans and offer practices to promote optimal sexual well-being. Examples of possible barriers that the MMSH may help to overcome include sexual trauma, sex as a maladaptive coping response to stress, sexual objectification and self-objectification, dissociation, problematic sexual scripts informed by exploitation or trauma, sexual compulsivity, problematic pornography use, poor interpersonal boundaries, low self-esteem or self-worth, or shame. What may be needed in healing processes or boundary management may be unique for each person.

Personal exploration of sexual health may be achieved by investigating each domain of the MMSH through mindful inquires as inspired by Hakomi practices (Kurtz, 1997). In the Hakomi process, a mindful state is used to explore with patients and increase self-awareness of feelings that may be linked to problems, barriers or other aspects leading to treatment-seeking. Identifying strengths of self-care and potential barriers or challenges to healthy expression or balance is possible through the guided process of connecting with specific and unique information that arises when employing mindful attention on internal processes. Mindful inquiries may act as prompts when used in the context of creating a state of focused, open, curious, non-judgmental, present, and body-centered attention. This process involves identifying the choice to witness or notice what is naturally or automatically occurring or arising within one's body. Information may be revealed through bodily sensations, impulses, images, colors, metaphorical representations, memories, words, or other messaging. This process may promote a different quality of consciousness that is experienced with focused attention noticing/noting that is different from ordinary thinking states and instead promotes being open to allow something unknown or unidentified to arise. This awareness rests in directly experiencing one's being while cultivating a fundamental warmth and compassionate quality that grows a sense of trust with oneself and fosters experiences of embodied aliveness (Trungpa, 2015).

There are several benefits of integrating mindful attention and connection with sexuality. Recent research shows that mindfulness-based approaches that include training of interoception to increase body awareness and body connection are effective in the treatment of sexual functioning concerns (Brotto, 2013; Brotto, Basson, et al., 2008; Carvalheira et al., 2017; Mehling et al., 2012; Mize, 2015; Silverstein et al., 2011). Given data suggesting that sexual dysfunction may arise from problematic pornography use, mindfulnessbased approaches may be applicable to multiple aspects of behavioral addictions. In addition to body awareness and body connection being important for treating sexual 
dysfunction and increasing sexual pleasure and satisfaction, they are also imperative for accessing the direct in-themoment information from one's inner experience that may be central for participation in ongoing dialogs of affirmative sexual consent. In the MMSH, being attuned and apprised of inner comfort, boundaries, pleasure, safety, sensations, and emotional and physical responses are important for optimizing communication in interpersonal sexual experiences that are dynamic and changing from moment to moment.

\section{TREATMENT FOR COMPULSIVE SEXUAL BEHAVIORS}

Integrating mindfulness (Chawla et al., 2010), interoceptive awareness (Mehling, 2016), and self-compassion (Germer \& Neff, 2013) into treatment interventions, self-care practice, and relapse prevention for people struggling with compulsive sexual behaviors have a growing body of evidenced-based research that suggests efficacy. Mindfulness and compassion training may empower individuals to take responsibility for working with their inner states to promote healing, growth, and positive change.

For people struggling with problematic sexual behaviors, sexual "acting out" may represent a maladaptive coping strategy and a "solution" for avoiding uncomfortable feelings of loneliness, shame, or other negative states. Therefore, teaching mindfulness may promote skill development involving paying attention to feeling and mental states, while tolerating present-moment experiences with curiosity, openness, non-judgment, and acceptance. This approach may introduce a new, kind, and gentle way of being with oneself, which may provide resiliency against negative affective states. Mindfulness also may permit access to a reservoir of experience in body and mind and promote integration, which is a useful intervention to address compartmentalization that may occur in individuals with compulsive sexual behaviors. Mindfulness-based practices may provide individuals a way to be present with their body, mind, emotions, desires, and impulses while feeling empowered with freedom and choice. This may represent a significant development for individuals who may often suffer from experiencing diminished control and feeling that need to escape being present with moment-to-moment experiences.

\section{CASE EXAMPLE}

Below is a composite case example that illustrates some features of how the MMSH may be used in clinical practice to help individuals seeking treatment for compulsive sexual behaviors.

Samantha was a 29-year-old woman seeking treatment for depression and compulsive sexual behaviors. During intake, she reported how her compulsive sexual behaviors contributed to multiple negative consequences including loss of jobs and relationships, financial instability, and repeatedly sending her nude pictures to men, despite promising herself that she would stop. As she shared more about the problems recurring in her life, it became clear that despite her insight, she continued to feel trapped by past habits and patterns of destructive sexual behaviors and relationships.

Samantha's history included being sexually abused by an adult when she was 9 years of age and was sexually assaulted by an adolescent peer at 13 years of age. Later in her teenager years, she began to abuse alcohol, heroin, crack cocaine, and cannabis. During the 7 years prior to entering treatment for compulsive sexual behaviors, Samantha was clean and sober, engaged in professional treatment for addiction, and participated in 12-step communities.

Samantha's sexual history includes significant pain, confusion, and shame. She said she believed that, "sex was the only asset I thought I had. My body and sex was a commodity. For a long time, I was unclear about this; I didn't see it. Now I realize that most of my sexual experiences came from a place of trauma. With all the guys I've been with, I have felt I had to perform a certain way for them. I allowed people to use and degrade me. At age 14, the first drug I ever had was attention from men. I'd do whatever they wanted sexually."

In therapy, Samantha identified a powerful barrier that interfered with her connecting within, to her own sense of inherent worthiness and personal power. Her past sexual trauma, abuse, and years of being sexually used had contributed to disconnecting herself from her power and from her open, integrated, vulnerable, and emotional self. She claimed that since she was a teenager, "my self-worth was defined by sexual attention from men." Early in her adolescence, she was conditioned to look outside of herself, to males in particular, for validation. She was not deeply connected to her emotions or her values, and she lacked confidence to pursue her goals or interests. She painfully discovered that, "I've been so closed off from my own feelings and from other people, as well as from knowing what it feels like to be truly alive and care about someone, including myself."

During the course of our mindfulness-based work together, she began to experience shifts of perception and beliefs about herself as she practiced being present and observing her inner self. These inner changes led to changing her sexual behaviors. "In stopping my sexual acting out, I'm being present inside myself. Before I was running and moving for such a long time. Sexual acting out was to escape anxiety, loneliness, and depression for me. The escape through sex was to try to make myself feel better, but it just made things worse."

As Samantha continued increasing her self-awareness, she more clearly witnessed her distorted thinking in the present moment, which was uncomfortable and concerning for her. "My perception of reality is not what is going on. I have no idea what reality is. I am super judgmental of myself and others. Now, I'm working on practicing these steps of awareness and mindfulness to see more clearly. Being newer in sexual recovery, it's painful to see more clearly when I am so disgusted with myself and my behavior, so it's difficult to cultivate this joy of living, because the sexual acting out was my barrier to joy and peace, since I was a teenager. It's painful to admit that I willingly engaged in behaviors that hurt my soul to get what I thought I needed. I would even play mind games with myself. I could have had 
sex with a hundred people, but there is no connection. It's empty. It's painful."

Samantha learned to bring compassion to her relationship with herself and that proved to be helpful for her in continuing to do the uncomfortable and challenging work of recovery. Her healing and growth continued. "Now, in recovery, my sexuality is changing. Before, I thought that my servicing people sexually was all that I was worth; now I am changing my perspective. Everything was about sex, my relationships at my job, how I related to men. It was all based on a manipulation of sex. I didn't have real female friendships, because I didn't put the time or energy into them because I could not use sex to manipulate females. The dynamics and interactions with women were not dictated by this sexual energy, so I didn't bother with or value female friends. With my sex addiction, I was trying to soothe myself on the inside and it didn't work. I was dying on the inside."

Mindfulness-based healing and recovery work support the practice of staying or returning to the present-centered direct experience of body, breath, and emotions. Mindful inquiries in sessions may be utilized to access information and explore core beliefs with people in treatment. Together, the therapist and patient may work together to promote understandings that may emerge from mindful inquires of bodily sensations and emotions. This mindful process may be a powerful and efficient way to access core material while creating shifts toward healing, integration, and growth.

The following is a transcript of a mindful inquiry session with Samantha early on in her treatment and shows how automatic reactions and her impulse to escape through distractions had created powerful habits. It is common for people to experience resistance to slowing down to mindfully feel inner states, particularly in people who have experienced trauma and addiction. Therefore, it is important to therapeutically create a safe space to be with inner states and reactions that are uncomfortable. In Table 1, we describe the steps of mindful inquiry and the purpose for each step. Mindful inquiries may involve the patient closing their eyes or using a soft gaze and focusing attention to their breath and body in order to attend to inner states. Although a therapist may offer suggestions as to where to direct attention, the patient's inner sovereignty is respected. They are asked to describe what they notice arising, with a direct experience of each mindful moment and the unknown territory is navigated together. It may be useful to offer a patient this descriptive metaphor of the power dynamic to assure patient's inner sovereignty; in this mindful inquiry process, the patient is driving with control behind the wheel, ultimately making choices of where to direct attention and what direction to turn toward for exploration of experience, while the therapist's role is one of being a passenger in the car providing a map and guiding by supporting the therapeutic process. A mindful inquiry transcript follows:

Samantha: “I'm noticing I'm trying to keep external noise and thoughts about what might happen next away."

Therapist: "Notice the impulse to push that away and now turn your attention to what you notice with your breath, your body."

Samantha: "I notice tension up in my shoulders, like when I'm running. It's an automatic reaction that happens and I feel I become small. When I relax, and let go now, I feel tension in my hips and jaw letting go. It feels unnatural to be awake and at rest at the same time." Therapist: "Yes, this is different and new. Return focus and attention with your exhale. What are you experiencing here?"

Samantha: "I feel the space between my nose and lips and the air of my exhale there. I feel the rise and fall of my chest. To be in this state is not natural for me. I feel energy and the impulse to fidget and adjust. I look for something ... a distraction. I feel like I want to jump out of my skin. It's not natural to feel calm. It feels so unnatural, to just stay still. That impulse to escape, to NOT BE HERE is very strong and frequent. I've been operating from a belief that, 'you can't hit a moving target, so keep moving!' Somehow, escape became my default mode. It's hard to be present and grounded in my body. I'm also noticing a default mode of protection saying, 'this is 'airy fairy' stuff'. I'm also noticing something I heard Brene Brown say, 'stand your sacred ground,."

Therapist: "That is what you are practicing now. This is what it feels like to grow in your practice and strength to STAY. To stay with your breath, your body, and your whole self while you 'stand your sacred ground'."

Samantha's communications illustrate differing thoughts and feelings arising within her mind and body. Habitual behaviors grounded in trauma may promote fighting against being still, and a pattern of behavior that she had once believed was serving as self-protection, has generated disconnection and self-harm over the longer term. The tendency to engage impulsively in behaviors may in a paradoxical manner be oriented toward creating a belief in separation. As Samantha identifies, her "default mode of protection" is the part that keeps her isolated, running, and looking to distractions. That part reacts as if a threat was being identified, pushing away, invalidating, and seeking to sabotage her experiencing a deeper connection with herself by the dismissive thoughts about the mindful inquiry being "airy-fairy stuff." She observes these thoughts and notices another message arising within. Samantha is noticing different aspects of herself with different messages, perspectives, and beliefs. Although structured measures relating these changes to clinical outcomes are lacking in this case, other clinical examples using this approach suggest that changes as describes above correlate with those using validated structured measures.

Samantha's case illustrates growth that may occur when practicing aspects of the MMSH. At present, she continues to utilize mindfulness-based approaches to explore mind and body states, regulate emotions, and use internal information to guide decision-making processes relating to substance use and sexual behaviors. Other case examples may rely more heavily on different aspects of the MMSH (Table 1), depending on individual presentations.

In Table 1, we describe the steps of a mindful inquiry and the purpose for each step. In Table 2, we describe how the MMSH specifically links to content of a mindful process in therapy sessions to access potential insights through mindful inquiry into patient's concerns. The table does not represent exhaustive lists of possibilities but rather provides examples 
as how mindful inquires may be undertaken and how the MMSH may be applied. This process should be individualized on a case-by-case basis to support people to develop and apply skills to promote mindful-connected sex.

\section{CONCLUSIONS}

In this article, we briefly review prior models of sexual health and mindfulness-based approaches and present a new MMSH that incorporates elements of eastern and western philosophies and may be used in the treatment of individuals with compulsive sexual behavior disorder. The model includes eight domains that are associated with potential barriers to health and ways in which the barriers may be addressed in clinical practice. In addition to helping people recover from compulsive sexual behavior disorder (including problematic pornography use), the MMSH may be useful in integrative sexual wellness education, sexual trauma recovery, and promoting sexual health more broadly.

Funding sources: MNP receives support from the Connecticut State Department of Mental Health and Addiction Services, the Connecticut Council on Problem Gambling; and, a Center of Excellence in Gambling Research Award from the National Center for Responsible Gaming. The funding agencies did not provide input or comment on the content of the manuscript, and the content of the manuscript reflects the contributions and thoughts of the authors and do not necessarily reflect the views of any funding agencies.

Authors' contribution: GRB developed the model, provided clinical care upon which the case presentation was based, and generated the first draft of the manuscript. MNP advised on the development of the model, provided input during preparation of the drafting of the manuscript, and edited and revised the manuscript. Both authors approved the submitted and revised versions of the manuscript.

Conflict of interest: The authors have no conflicts of interest with respect to the content of this manuscript. Dr. MNP has received financial support or compensation for the following: has consulted for and advised Shire, INSYS, RiverMend Health, Opiant/Lakelight Therapeutics, and Jazz Pharmaceuticals; has received unrestricted research support from Mohegan Sun Casino and grant support from the National Center for Responsible Gaming; and has consulted for legal and gambling entities on issues related to impulse control disorders. The other author reports no disclosures.

\section{REFERENCES}

Astin, J. A., Shapiro, S. L., Eisenberg, D. M., \& Forys, K. L. (2003). Mind-body medicine: State of the science, implications for practice. The Journal of the American Board of Family Practice, 16(2), 131-147. doi:10.3122/jabfm.16.2.131
Basson, R. (2002). A model of women's sexual arousal. Journal of Sex \&Marital Therapy, 28(1), 1-10. doi:10.1080/00926230 2317250963

Basson, R. (2005). Women's sexual dysfunction: Revised and expanded definitions. Canadian Medical Association Journal, 172(10), 1327-1333. doi:10.1503/cmaj.1020174

Blycker, G. (2018). Mindful model of sexual health. Retrieved from http://www.halsosamtherapy.com/mindful-modelof-sexual-health/

Bowen, S., Chawla, N., Collins, S. E., Witkiewitz, K., Hsu, S., Grow, J., Clifasefi, S., Garner, M., Douglass, A., Larimer, M. E., \& Marlatt, A. (2009). Mindfulness-based relapse prevention for substance use disorders: A pilot efficacy trial. Substance Abuse, 30(4), 295-305. doi:10.1080/088970709 03250084

Bowen, S., Chawla, N., \& Marlatt, G. (2011). Mindfulness-based relapse prevention for addictive behaviors. A clinician guide. New York/London: The Guilford press.

Bowen, S., \& Marlatt, A. (2009). Surfing the urge: Brief mindfulness-based intervention for college student smokers. Psychology of Addictive Behaviors, 23(4), 666-671. doi:10.1037/ a0017127

Brewer, J. A., Bowen, S., Smith, J. T., Marlatt, G. A., \& Potenza, M. N. (2010). Mindfulness-based treatments for co-occurring depression and substance use disorders: What can we learn from the brain? Addiction, 105(10), 1698-1706. doi:10.1111/ j.1360-0443.2009.02890.x

Brewer, J. A., Davis, J. H., \& Goldstein, J. (2013). Why is it so hard to pay attention, or is it? Mindfulness, the factors of awakening and reward-based learning. Mindfulness, 4(1), 75-80. doi:10.1007/s12671-012-0164-8

Brewer, J. A., Worhunsky, P. D., Gray, J., Tang, Y. Y., Weber, J., \& Kober, H. (2011). Meditation experience is associated with differences in default mode network activity and connectivity. Proceedings of the National Academy of Sciences of the United States of America, 108(50), 20254-20259. doi:10.1073/ pnas. 1112029108

Bridges, A. J., Sun, C. F., Ezzell, M. B., \& Johnson, J. (2016). Sexual scripts and the sexual behavior of men and women who use pornography. Sexualization, Media, \& Society, 2(4), 2374623816668275. doi:10.1177/2374623816668275

Bridges, A. J., Wosnitzer, R., Scharrer, E., Sun, C., \& Liberman, R. (2010). Aggression and sexual behavior in best-selling pornography videos: A content analysis update. Violence Against Women, 16(10), 1065-1085. doi:10.1177/1077801210382866

Brotto, L. A. (2013). Mindful sex. Canadian Journal of Human Sexuality, 22(2), 63-68. doi:10.3138/cjhs.2013.2132

Brotto, L. A., Basson, R., \& Luria, M. (2008). A mindfulnessbased group psychoeducational intervention targeting sexual arousal disorder in women. The Journal of Sexual Medicine, 5(7), 1646-1659. doi:10.1111/j.1743-6109.2008.00850.x

Brotto, L. A., Chivers, M. L., Millman, R. D., \& Albert, A. (2016). Mindfulness-based sex therapy improves genital-subjective arousal concordance in women with sexual desire/arousal difficulties. Archives of Sexual Behavior, 45(8), 1907-1921. doi:10.1007/s10508-015-0689-8

Brotto, L. A., Krychman, M., \& Jacobson, P. (2008). Eastern approaches for enhancing women's sexuality: Mindfulness, acupuncture, and yoga (CME). The Journal of Sexual Medicine, 5(12), 2741-2748. doi:10.1111/j.1743-6109. 2008.01071.x 
Brotto, L. A., Mehak, L., \& Kit, C. (2009). Yoga and sexual functioning: A review. Journal of Sex \& Marital Therapy, 35(5), 378-390. doi:10.1080/00926230903065955

Brotto, L. A., Seal, B. N., \& Rellini, A. (2012). Pilot study of a brief cognitive behavioral versus mindfulness-based intervention for women with sexual distress and a history of childhood sexual abuse. Journal of Sex \& Marital Therapy, 38(1), 1-27. doi:10.1080/0092623X.2011.569636

Carnes, P., \& Adams, K. M. (2013). Clinical management of sex addiction. London, UK: Routledge.

Carvalheira, A., Price, C., \& Neves, C. F. (2017). Body awareness and bodily dissociation among those with and without sexual difficulties: Differentiation using the scale of body connection. Journal of Sex \& Marital Therapy, 43(8), 801-810. doi:10.1080/0092623X.2017.1299823

Chawla, N., Collins, S., Bowen, S., Hsu, S., Grow, J., Douglass, A., \& Marlatt, G. A. (2010). The Mindfulness-Based Relapse Prevention Adherence and Competence Scale: Development, interrater reliability, and validity. Psychotherapy Research, 20(4), 388-397. doi:10.1080/10503300903544257

Crawford, M., \& Popp, D. (2003). Sexual double standards: A review and methodological critique of two decades of research. Journal of Sex Research, 40(1), 13-26. doi:10.1080/ 00224490309552163

Diamond, L. M. (2003). What does sexual orientation orient? A biobehavioral model distinguishing romantic love and sexual desire. Psychological Review, 110(1), 173-192. doi:10.1037/ 0033-295X.110.1.173

Diamond, L. M. (2008). Sexual fluidity. Cambridge, MA: Harvard University Press.

Douglas, J. M., Jr., \& Fenton, K. A. (2013). Understanding sexual health and its role in more effective prevention programs: Los Angeles, CA: Sage Publications.

Dowman, K. (1996). Sky dancer: The secret life and songs of Lady Yeshe Tsogyel. Ithaca, NY: Snow Lion Publications.

Easwaran, E. (2007). The Bhagavad Gita (Classics of Indian Spirituality). Tomales, CA: Nilgiri Press.

Ellis, H. (1911). Studies in the psychology of sex: Sex in relation to society. Philadelphia, PA: FA Davis Company.

Epstein, M. (2013). Thoughts without a thinker: Psychotherapy from a Buddhist perspective. New York, NY: Basic Books.

Erez, G., Pilver, C. E., \& Potenza, M. N. (2014). Gender-related differences in the associations between sexual impulsivity and psychiatric disorders. Journal of Psychiatric Research, 55, 117-125. doi:10.1016/j.jpsychires.2014.04.009

Garanzini, S., Yee, A., Gottman, J., Gottman, J., Cole, C., Preciado, M., \& Jasculca, C. (2017). Results of Gottman method couples therapy with gay and lesbian couples. Journal of Marital and Family Therapy, 43(4), 674-684. doi:10.1111/ jmft. 12276

Garrison, K. A., Zeffiro, T. A., Scheinost, D., Constable, R. T., \& Brewer, J. A. (2015). Meditation leads to reduced default mode network activity beyond an active task. Cognitive, Affective \& Behavioral Neuroscience, 15(3), 712-720. doi:10.3758/s13415015-0358-3

Germer, C. K., \& Neff, K. D. (2013). Self-compassion in clinical practice. Journal of Clinical Psychology, 69(8), 856-867. doi:10.1002/jclp.22021

Gola, M., \& Potenza, M. N. (2018). The proof of the pudding is in the tasting: Data are needed to test models and hypotheses related to compulsive sexual behaviors. Archives of Sexual Behavior, 47(5), 1323-1325. doi:10.1007/s10508018-1167-x

Gorman, S., Monk-Turner, E., \& Fish, J. N. (2010). Free adult Internet web sites: How prevalent are degrading acts? Gender Issues, 27(3-4), 131-145. doi:10.1007/s12147-010-9095-7

Haas, M. (2013). Dakini power: Twelve extraordinary women shaping the transmission of Tibetan Buddhism in the West. Boston, MA: Shambhala Publications.

Hendershot, C. S., Witkiewitz, K., George, W. H., \& Marlatt, G. A. (2011). Relapse prevention for addictive behaviors. Substance Abuse Treatment, Prevention, and Policy, 6(1), 17. doi:10.1186/ 1747-597X-6-17

Kabat-Zinn, J., \& Hanh, T. N. (1990). Full catastrophe living: Using the wisdom of your body and mind to face stress, pain, and illness. New York, NY: Bantam Doubleday Dell Publishing Group, Inc.

Kingston, D. A. (2017). Moving forward on hypersexuality. Archives of Sexual Behavior, 46(8), 2257-2259. doi:10.1007/ s10508-017-1059-5

Kinsey, A., Pomeroy, W., \& Martin, C. (1948). Sexual behavior in the human male. Philadelphia, PA: W. B. Saunders Company.

Kinsey, A., Pomeroy, W., Martin, C., \& Gebhard, P. (1953). Sexual behavior in the human female. Philadelphia, PA: W. B. Saunders Company.

Kor, A., Zilcha-Mano, S., Fogel, Y. A., Mikulincer, M., Reid, R. C., \& Potenza, M. N. (2014). Psychometric development of the Problematic Pornography Use Scale. Addictive Behaviors, 39(5), 861-868. doi:10.1016/j.addbeh.2014.01.027

Kornfield, J. (2009). The wise heart: A guide to the universal teachings of Buddhist psychology. New York, NY: Bantam Books.

Kraus, S. W., Krueger, R. B., Briken, P., First, M. B., Stein, D. J., Kaplan, M. S., Voon, V., Abdo, C. H. N., Grant, J. E., Atalla, E., \& Reed, G. M. (2018). Compulsive sexual behaviour disorder in the ICD-11. World Psychiatry, 17(1), 109-110. doi:10.1002/wps.20499

Kraus, S. W., Martino, S., \& Potenza, M. N. (2016). Clinical characteristics of men interested in seeking treatment for use of pornography. Journal of Behavioral Addictions, 5(2), $169-178$. doi:10.1556/2006.5.2016.036

Kurtz, R. (1997). Body-centered psychotherapy: The Hakomi method: The integrated use of mindfulness, nonviolence and the body. Mendocino, CA: Life Rhythm.

Leiblum, S. R. (2006). Principles and practice of sex therapy. New York, NY: Guilford Press.

Loizzo, J. (2014). Meditation research, past, present, and future: Perspectives from the Nalanda contemplative science tradition. Annals of the New York Academy of Sciences, 1307(1), 43-54. doi:10.1111/nyas. 12273

Loizzo, J. J. (2016). The subtle body: An interoceptive map of central nervous system function and meditative mind-brainbody integration. Annals of the New York Academy of Sciences, 1373(1), 78-95. doi:10.1111/nyas.13065

Maltz, W. (1995). The Maltz hierarchy of sexual interaction. Sexual Addiction \& Compulsivity, 2(1), 5-18. doi:10.1080/ 10720169508400062

Maltz, W. (2001). The sexual healing journey: A guide for survivors of sexual abuse. New York, NY: Quill. 
Masters, W. H., Johnson, V. E., \& Kolodny, R. C. (1982). Masters \& Johnson on sex and human loving. Bostan, MA: Little, Brown and Company.

McCarthy, B., \& Wald, L. M. (2013). Mindfulness and good enough sex. Sexual and Relationship Therapy, 28(1-2), 39-47. doi:10.1080/14681994.2013.770829

McCarthy, B. W. (2004). Coping with erectile dysfunction: How to regain confidence \& enjoy great sex. Oakland, CA: New Harbinger.

Mehling, W. (2016). Differentiating attention styles and regulatory aspects of self-reported interoceptive sensibility. Philosophical Transactions of the Royal Society of London, Series B, 371(1708), 20160013. doi:10.1098/rstb. 2016.0013

Mehling, W. E., Price, C., Daubenmier, J. J., Acree, M., Bartmess, E., \& Stewart, A. (2012). The multidimensional assessment of interoceptive awareness (MAIA). PLoS One, 7(11), e48230. doi:10.1371/journal.pone.0048230

Meston, C. M., Goldstein, I., Davis, S., \& Traish, A. (2005). Women's sexual function and dysfunction: Study, diagnosis and treatment. London, UK: CRC Press.

Miller, L., Balodis, I. M., McClintock, C. H., Xu, J., Lacadie, C. M., Sinha, R., \& Potenza, M. N. (2018). Neural correlates of personalized spiritual experiences. Cerebral Cortex. Advance online publication. doi:10.1093/cercor/bhy 102

Mize, S. J. (2015). A review of mindfulness-based sex therapy interventions for sexual desire and arousal difficulties: From research to practice. Current Sexual Health Reports, 7(2), 89-97. doi:10.1007/s11930-015-0048-8

Ogden, P., Minton, K., Pain, C., Siegel, D. J., \& van der Kolk, B. (2006). Trauma and the body: A sensorimotor approach to psychotherapy. New York, NY: W. W. Norton \& Company.

Potki, R., Ziaei, T., Faramarzi, M., Moosazadeh, M., \& Shahhosseini, Z. (2017). Bio-psycho-social factors affecting sexual self-concept: A systematic review. Electronic Physician, 9(9), 5172-5178. doi:10.19082/5172

Price, C. (2005). Body-oriented therapy in recovery from child sexual abuse: An efficacy study. Alternative Therapies in Health and Medicine, 11(5), 46.

Price, C., \& Smith-DiJulio, K. (2016). Interoceptive awareness is important for relapse prevention: Perceptions of women who received mindful body awareness in substance use disorder treatment. Journal of Addictions Nursing, 27(1), 32-38. doi:10.1097/JAN.0000000000000109

Price, C. J., \& Hooven, C. (2018). Interoceptive awareness skills for emotion regulation: Theory and approach of mindful awareness in body-oriented therapy (MABT). Frontiers in Psychology, 9, 798. doi:10.3389/fpsyg.2018.00798

Price, C. J., \& Thompson, E. A. (2007). Measuring dimensions of body connection: Body awareness and bodily dissociation. The Journal of Alternative and Complementary Medicine, 13(9), 945-953. doi:10.1089/acm.2007.0537

Price, C. J., Thompson, E. A., \& Cheng, S. C. (2017). Scale of body connection: A multi-sample construct validation study. PLoS One, 12(10), e0184757. doi:10.1371/journal.pone.0184757

Price, C. J., Wells, E. A., Donovan, D. M., \& Rue, T. (2012). Mindful awareness in body-oriented therapy as an adjunct to women's substance use disorder treatment: A pilot feasibility study. Journal of Substance Abuse Treatment, 43(1), 94-107. doi:10.1016/j.jsat.2011.09.016

Silverstein, R. G., Brown, A.-C. H., Roth, H. D., \& Britton, W. B. (2011). Effects of mindfulness training on body awareness to sexual stimuli: Implications for female sexual dysfunction. Psychosomatic Medicine, 73(9), 817-825. doi:10.1097/PSY. 0b013e318234e628

Stephenson, K. R., \& Kerth, J. (2017). Effects of mindfulnessbased therapies for female sexual dysfunction: A meta-analytic review. The Journal of Sex Research, 54(7), 832-849. doi:10.1080/00224499.2017.1331199

Sun, C., Bridges, A., Johnson, J. A., \& Ezzell, M. B. (2016). Pornography and the male sexual script: An analysis of consumption and sexual relations. Archives of Sexual Behavior, 45(4), 983-994. doi:10.1007/s10508-014-0391-2

Tekin, A., Meriç, C., Sağbilge, E., Kenar, J., Yayla, S., Özer, Ö. A., \& Karamustafalioğlu, O. (2016). The relationship between childhood sexual/physical abuse and sexual dysfunction in patients with social anxiety disorder. Nordic Journal of Psychiatry, $\quad 70(2), \quad 88-92 . \quad$ doi:10.3109/08039488.2015. 1053097

Trungpa, C. (2015). Mindfulness in action: Making friends with yourself through meditation and everyday awareness. Boston, MA: Shambhala Publications.

Turban, J. L., Potenza, M. N., Hoff, R. A., Martino, S., \& Kraus, S. W. (2017). Psychiatric disorders, suicidal ideation, and sexually transmitted infections among post-deployment veterans who utilize digital social media for sexual partner seeking. Addictive Behaviors, 66, 96-100. doi:10.1016/j. addbeh.2016.11.015

Van der Kolk, B. A. (2015). The body keeps the score: Brain, mind, and body in the healing of trauma. New York, NY: Penguin Books.

Van der Kolk, B. A., Pelcovitz, D., Roth, S., Mandel, F. S., McFarlane, A., \& Herman, J. L. (1996). Dissociation, somatization, and affect dysregulation: The complexity of adaptation of trauma. The American Journal of Psychiatry, 153(7 Suppl.), 83-93. doi:10.1176/ajp.153.7.83

Van Gordon, W., Shonin, E., \& Griffiths, M. D. (2016). Meditation awareness training for the treatment of sex addiction: A case study. Journal of Behavioral Addictions, 5(2), 363-372. doi:10.1556/2006.5.2016.034

Walton, M. T., Cantor, J. M., Bhullar, N., \& Lykins, A. D. (2017). Hypersexuality: A critical review and introduction to the "sexhavior cycle". Archives of Sexual Behavior, 46(8), 2231-2251. doi:10.1007/s10508-017-0991-8

Witkiewitz, K., Bowen, S., Harrop, E. N., Douglas, H., Enkema, M., \& Sedgwick, C. (2014). Mindfulness-based treatment to prevent addictive behavior relapse: Theoretical models and hypothesized mechanisms of change. Substance Use \& Misuse, 49(5), 513-524. doi:10.3109/10826084.2014. 891845

World Health Organization [WHO]. (2006). Defining sexual health: Report of a technical consultation on sexual health, 28-31 January 2002. Geneva, Switzerland: World Health Organization. 